\title{
A FEMDEM NUMERICAL MODEL STUDY OF RUBBLE-MOUND STRUCTURES ARMOURED WITH CONCRETE ARMOUR UNITS
}

John-Paul Latham, Eleni Anastasaki, Jiansheng Xiang

Imperial College London, Earth Science and Engineering Department

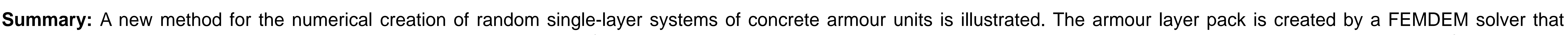

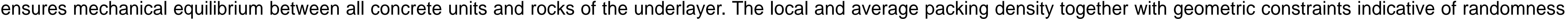

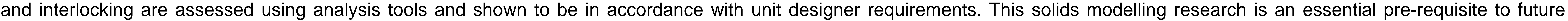
simulation of the armour layer response to wave loading and more realistic modelling of wave run-up and overtopping on rubble-mound structures.

\section{INTRODUCTION}

The photograph shows a highly complex interlocked structure of a random single-layer system of CORE-LOCTM units. To benefit from numerical models in studies of the mechanical behaviour of such rubble-mound breakwaters and coastal structures, the creation of a realistic granular solid skeleton is the first step. Research has been undertaken to create such models using the multi-body FEMDEM code, 'Y3D' [1] and associated numerical simulation tools. A deposition code, POSITIT, was also developed.

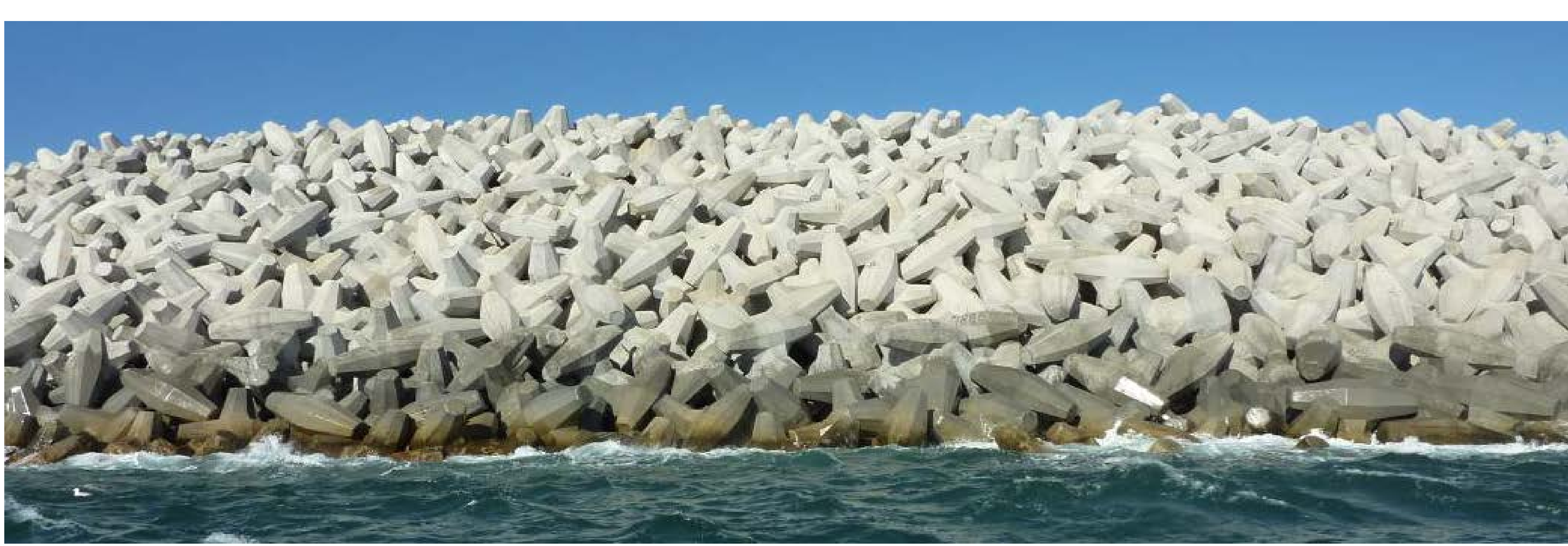

DESIGN AND CREATION OF REALISTIC TEST SECTION

An impermeable sloping panel with physical dimensions matching the cross section of a realistic breakwater is designed and meshed. Here, we dimension the structure to be compatible with placement of 20 rows of $8 \mathrm{~m}^{3}$ units, (Height $\mathrm{H}=3.31 \mathrm{~m}$ ). Once modelled, the structure can also be rescaled.

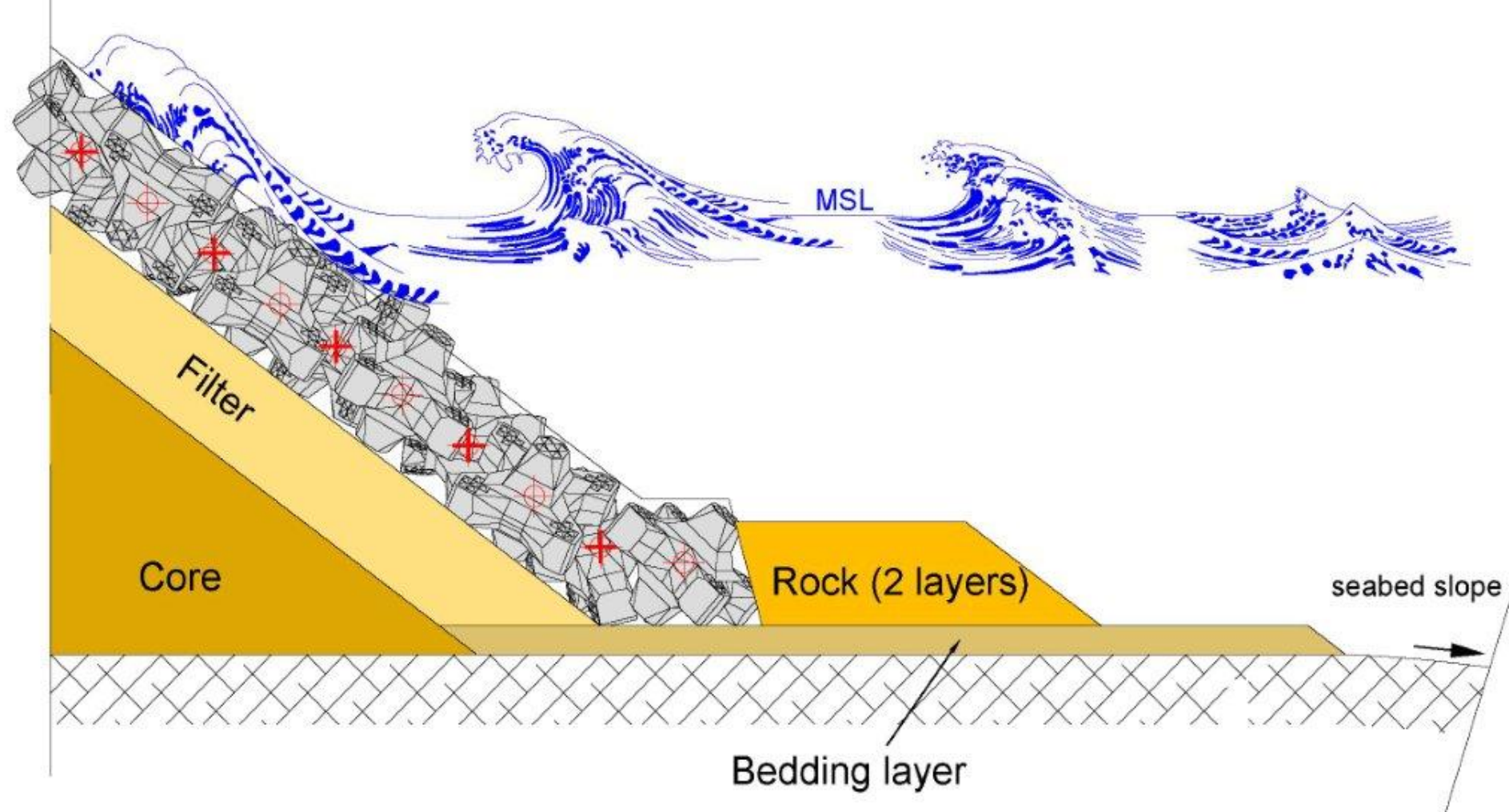

\section{Particle selection and mesh}

Different shapes and sizes of realistic rocks and different types of concrete armour units are stored in a digital shape library with appropriate resolution meshes.

\section{$\infty 0^{\circ} \cdot \log$}

Creation of a rough underlayer

Realistic rough underlayers with a toe berm and consisting of rocks of the correct characteristic weight were constructed. The number, sizes and shapes of the deposited rocks were selected to create layers that conform to design rules for underlayer thickness and permeability. Roughness and packing density of rock layers can be controlled.
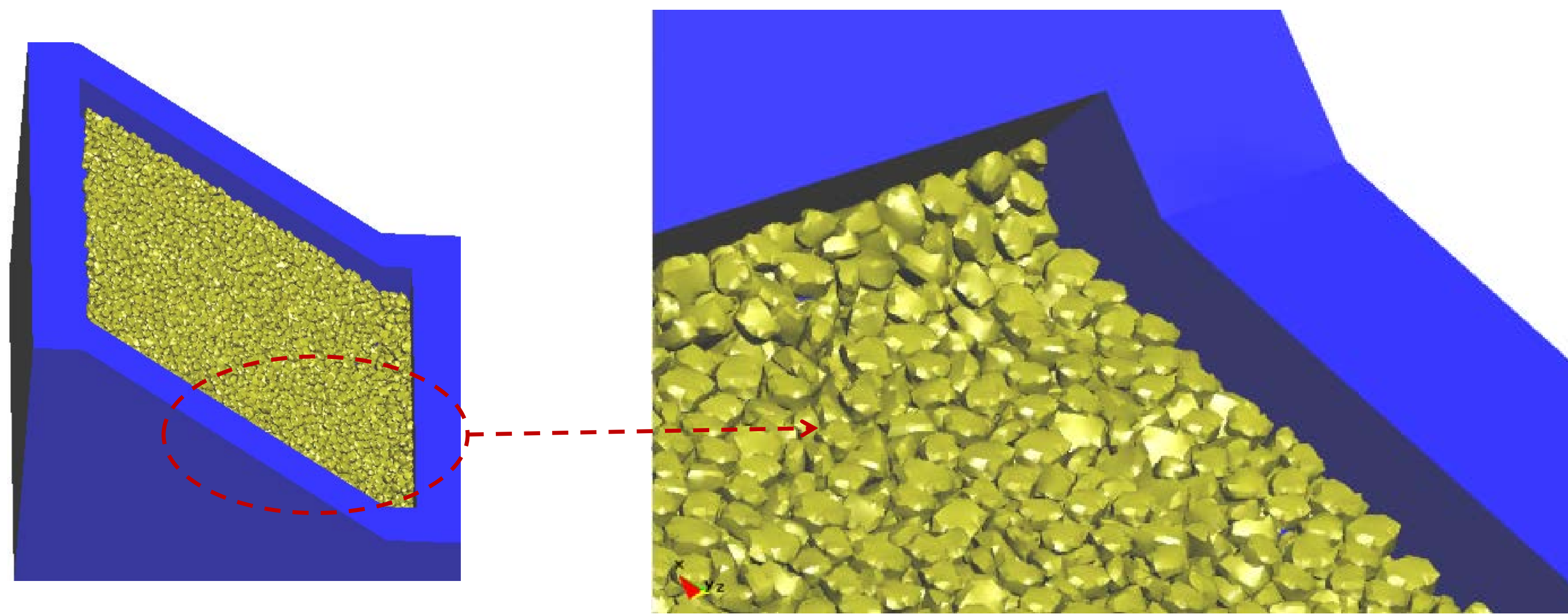

Target placement grid

Grid patterns for placement on rough or smooth slopes were automatically calculated given the target positions of the units (horizontal and vertical distances between the units). Reference directions were assigned to the concrete units in order to develop strategies leading to the high packing densities required and to enable the randomness of axial orientations to be examined on a stereo-net plot.

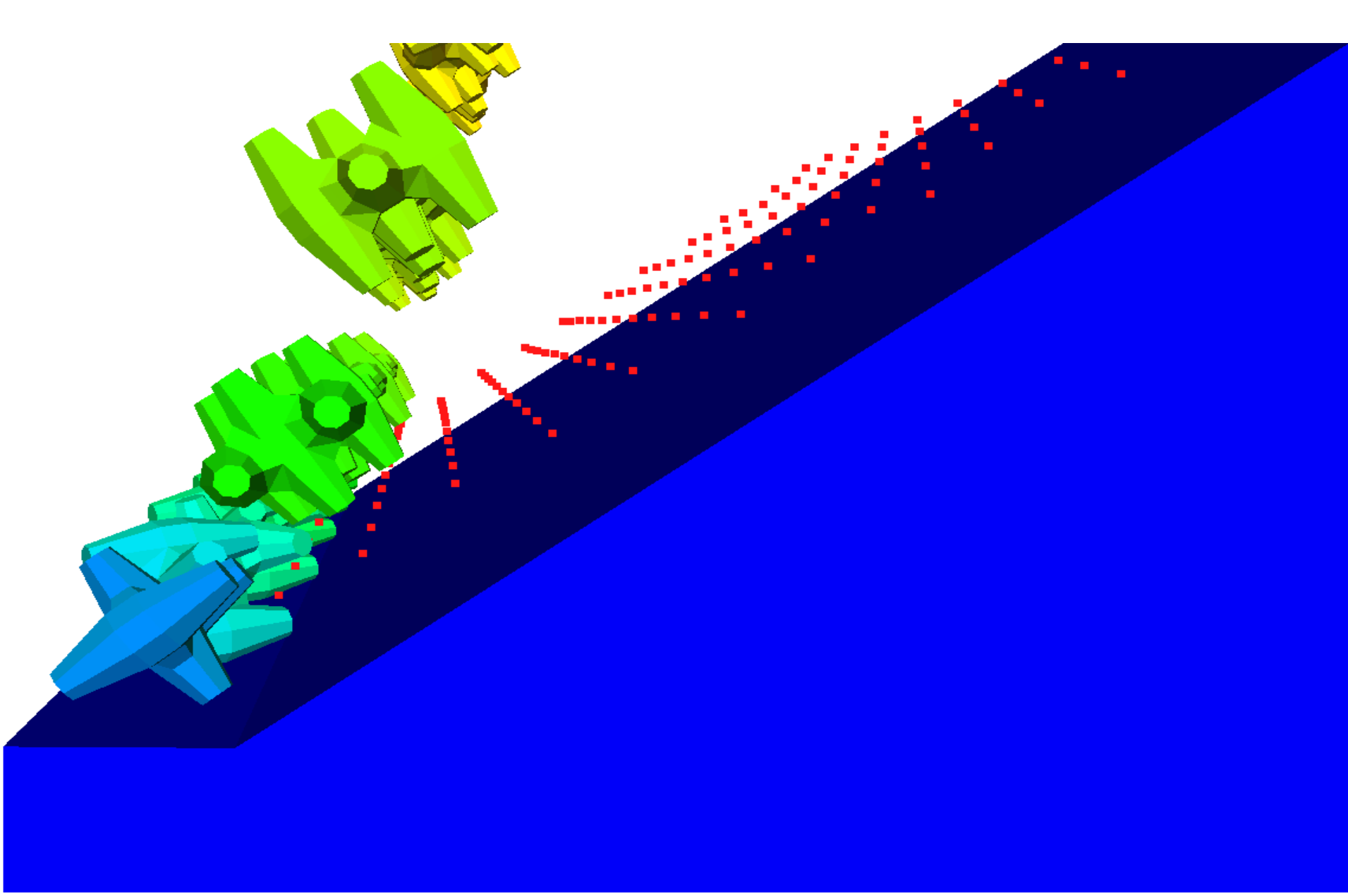

Depositing units with POSITIT, coupled to Y3D, on a smooth layer

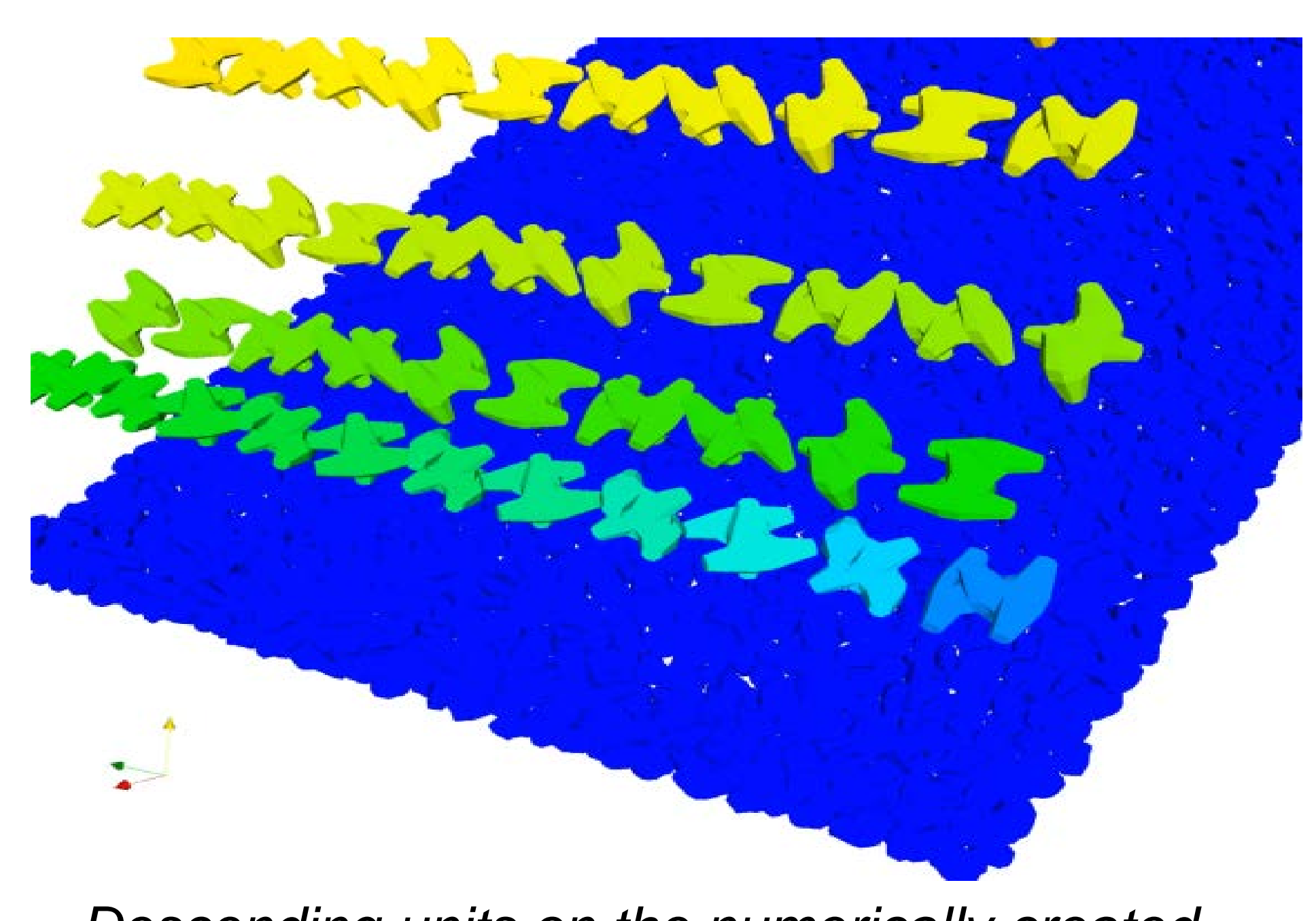

Descending units on the numerically created rough underlayer
FINAL PLACEMENT OF CONCRETE ARMOUR UNITS SHOWING CONTACTS

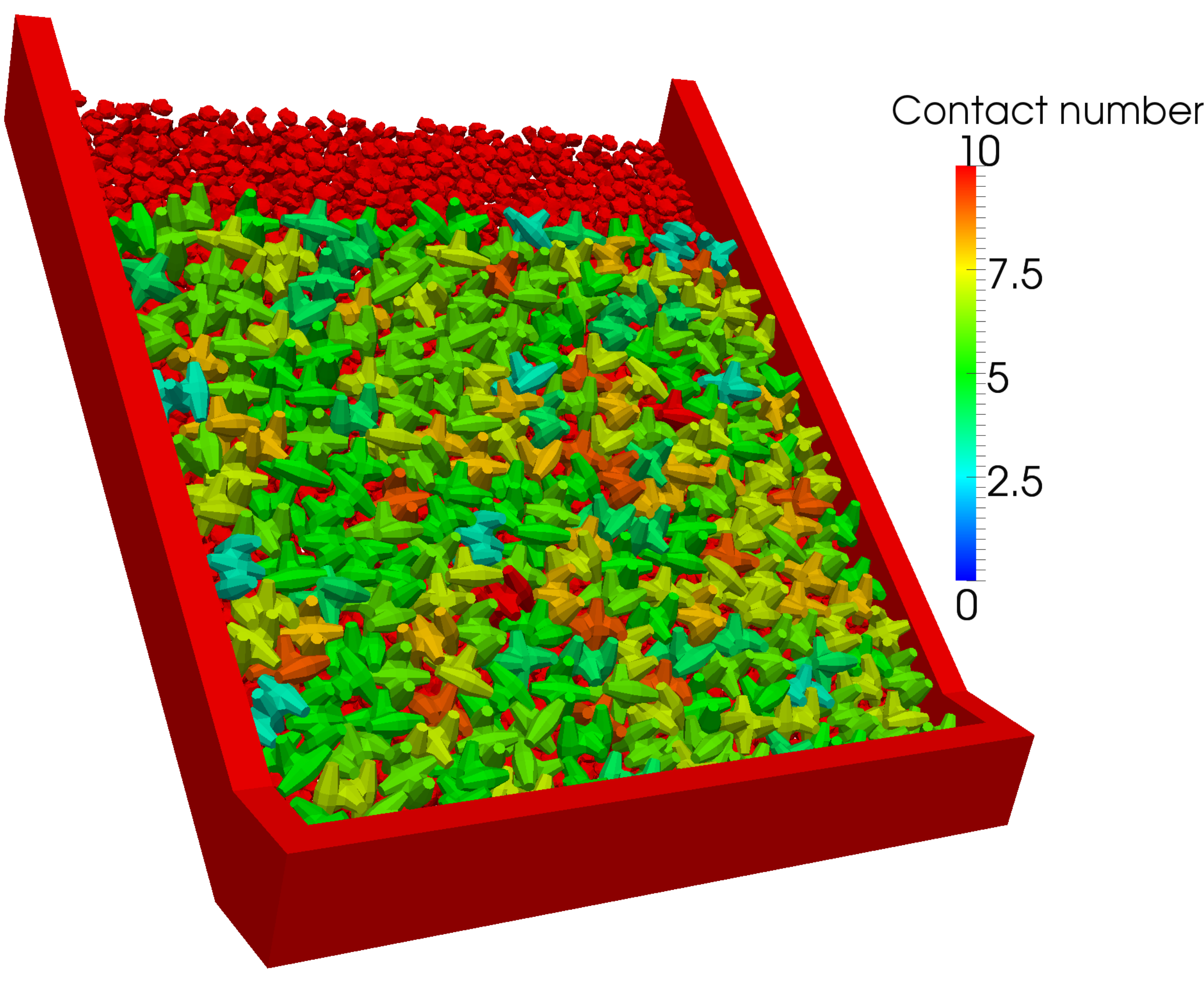

\section{ANALYSIS}

A great benefit of numerical methods is the ability to interrogate variables and processes with analysis tools. Here, we focus simply on the state of the final packs created. The potential for FEMDEM codes to model dynamic processes in armour layers was illustrated previously $[2,3]$. Velocity magnitude and direction, the number of contacts per unit (i.e. coordination number), contact forces and stresses within all units, can be analysed during the placement itself and at the final position of rest. Properties such as number per square meter, solid volume fraction (\%) in a bounded volume, can be automatically calculated. Local dimensionless packing density $\Phi$, on a per unit or a per row basis or as average $\Phi$ for the whole structure can be accurately calculated using a new method. Here, we show results for coordination number, maximum contact force per unit, the position of centroids and a stereographic plot for a placement of $8 \mathrm{~m}^{3}$ units with average $\Phi=0.60$. Different packs for different densities can also be created. A whole range of statistical parameters can be used to quantify the heterogeneity of the pack.

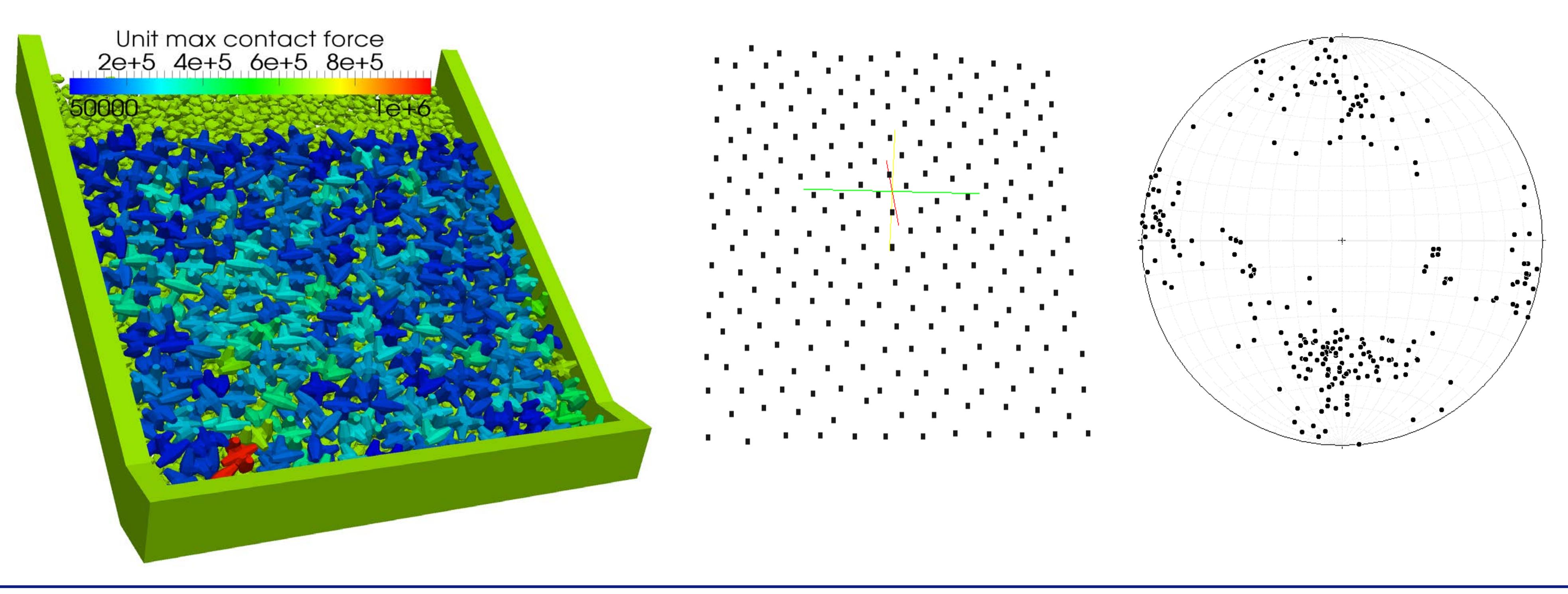

\section{PLACEMENT OF DIFFERENT ARMOUR UNITS}

Realistic armour layers consisting of different types of concrete armour units can be numerically created

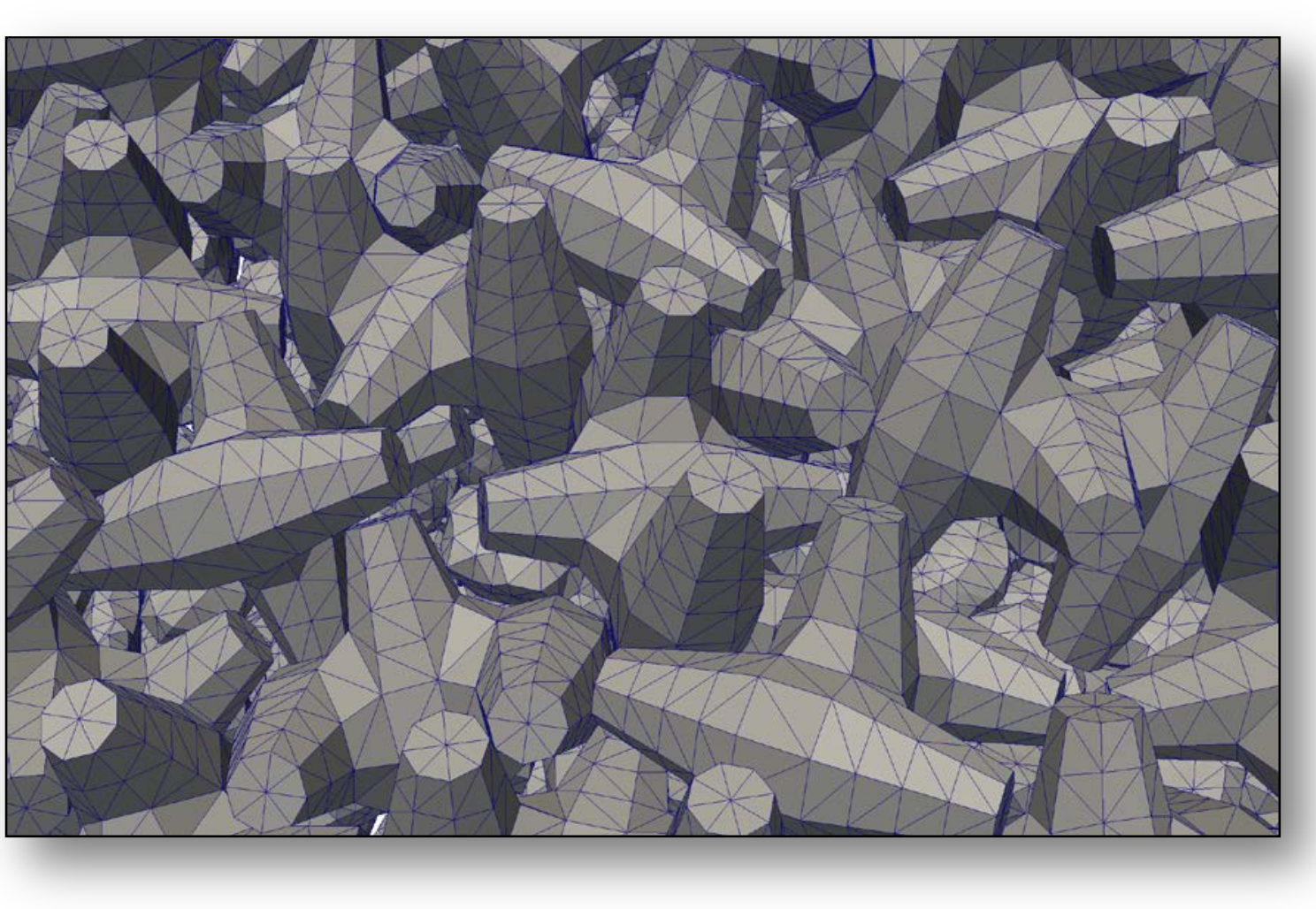

CORE-LOCTM

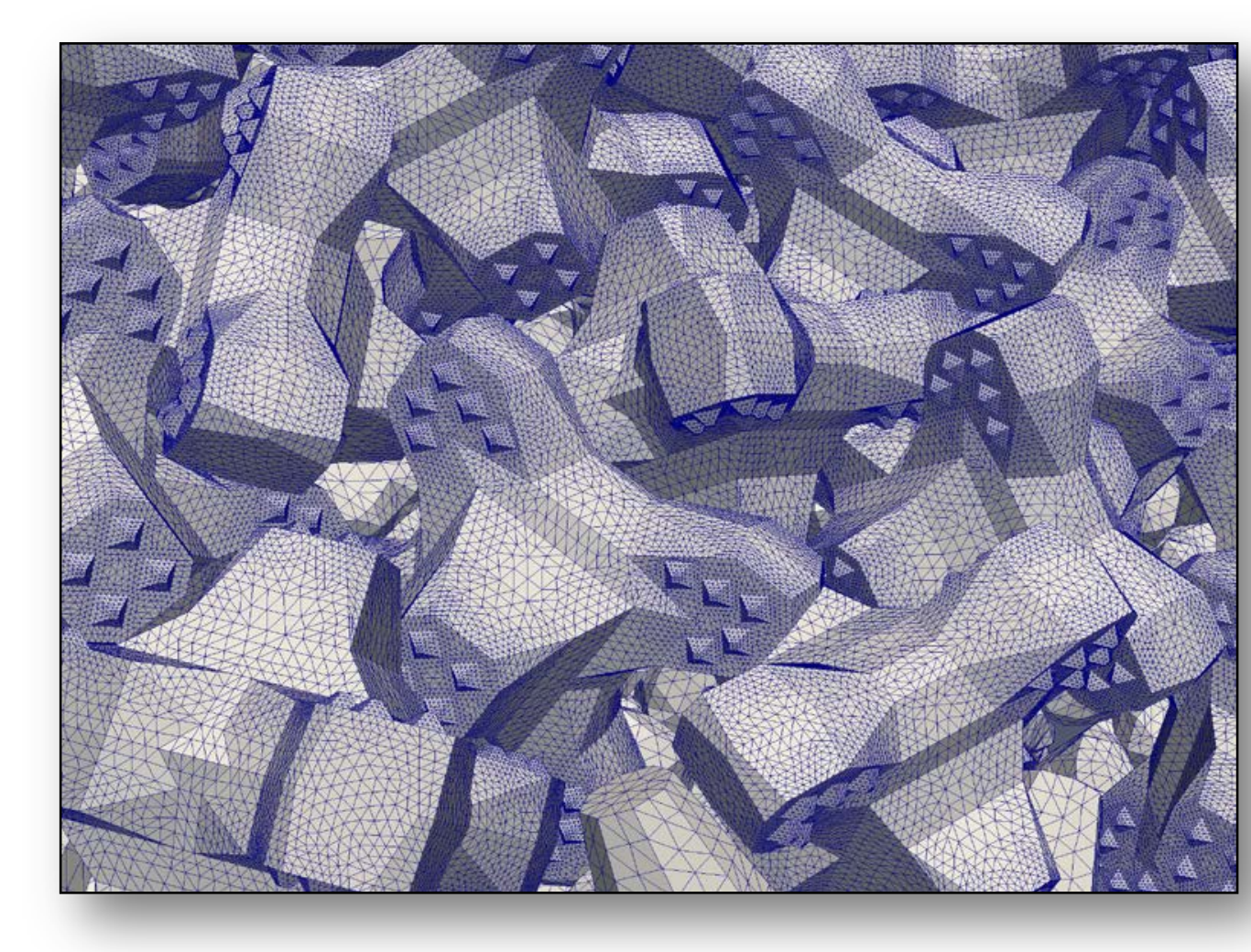

ACCROPODETM $/$

\section{CONCLUSIONS}

Realistic packs satisfying the placement criteria of unit designers were successfully modelled with FEMDEM. Models with different average $\Phi$ provide a starting point to evaluate the role of initial $\Phi$ on stability and settlement under various forms of disturbance. The construction of realistic solids models shown here is an essential pre-requisite to the simulation of the armour layer response to wave loading in coupled models [4] and more realistic modelling of wave run-up and overtopping on rubble-mound structures.

\section{References}

[1] Xiang, J., Muniziza, A., and Latham, J.P.., (2009). Finite strain, finite rotation quadratic te [2] Laham, J.P. (international Conference on Coastal Structures, Yokohama, Japan. September 6-8. [4] Xiang, J., Latham, J.-P., Vire A., Anastasaki, E., Pain, C.C, Mitthaler, F. 2012. Simulation tools for numerical breakwater models including Contacts: j.p.latham@imperial.ac.uk, e.anastasaki@imperial.ac.uk, j.xiang@imperial.ac.uk.

EPSRC

